\title{
Roles of Hedgehog signaling pathway in adipogenic differentiation potential of porcine adipose-derived mesenchymal stem cells
}

\author{
Caiyun Fan ${ }^{1}$, Yunhai Zhang ${ }^{1}$, Juhua Wang ${ }^{1}$, Jianbo Cheng ${ }^{1 *}$
}

\author{
${ }^{1}$ Anhui Agricultural University, College of Animal Science and Technology, Anhui Provincial Laboratory for Local Livestock and Poultry Genetic \\ Resource Conservation and Breeding, Hefei, Anhui, China.
}

\begin{abstract}
This study examined the effects of purmorphamine and cyclopamine, classical agonists and inhibitors of the Hedgehog (Hh) signaling pathway, in the adipogenic differentiation of porcine adipose-derived mesenchymal stem cells (AMSC) to investigate the roles underlying adipogenic differentiation in AMSC. Porcine-derived AMSC were established, and the Hh signaling pathway was activated or inhibited by treatment with purmorphamine or cyclopamine. The adipogenic differentiation of the porcine AMSC was then analyzed by Oil Red O staining. The expression levels of Hh signaling pathway factors and adipogenic transcription factors were determined using quantitative real-time polymerase chain reaction and western blot analysis. We verified that the expression levels of positive regulators of the Hh pathway (Smo, Gli1, Gli2, and Gli3) decreased during adipogenesis, whereas those of negative regulators (Ptcl and Ptc2) increased. Purmorphamine can inhibit the adipogenic differentiation of porcine AMSC in vitro culture. In addition, both the expression of the CCAAT/enhancerbindingprotein- $\alpha$ and that of the peroxisome proliferator-activated receptor- $\gamma$ decreased in the presence of purmorphamine. By contrast, cyclopamine had no significant effect on the adipogenic differentiation of porcine AMSC. The Hh signaling pathway inhibits the adipogenic differentiation potential of porcine AMSC.
\end{abstract}

Key Words: adipogenesis, differentiation, expression, pig

\section{Introduction}

Adipogenesis is a process by which mesenchymal precursor cells differentiate into adipocytes, which store lipids and serve as a central regulator of metabolism (Rosen et al., 2000; Farmer, 2006; Rosen and MacDougald, 2006). Identification of the key factors that control adipocyte differentiation is very important to the understanding of adipose tissue biology, pathology, and the mechanism of adipose tissue deposition (Farmer, 2006; Poulos et al., 2016). Over the past several years, the field of adipogenesis has seen an upsurge in the number of reports implicating locally secreted or circulating extracellular factors as regulators of preadipocyte differentiation (Bennett et al., 2002; Rosen and MacDougald, 2006; Prestwich and MacDougald, 2007). Extracellular signaling pathways known to affect adipogenesis include Wnt, bone morphogenetic protein

Received: February 4, 2017

Accepted: January 11, 2018

*Corresponding author: chengjianbofcy@163.com

Copyright (c) 2018 Sociedade Brasileira de Zootecnia. This is an Open Access article distributed under the terms of the Creative Commons Attribution License (http://creativecommons.org/licenses/by/4.0/), which permits unrestricted use, distribution, and reproduction in any medium, provided the original work is properly cited.
(BMP), and Hedgehog (Hh) (Bennett et al., 2002; Prestwich and MacDougald, 2007).

The Hh pathway regulates the cell fates of precursor cells (McMahon et al., 2003). Secreted Hh proteins bind to a cell surface receptor complex consisting of negatively acting patched (Ptc) receptors (Ptc1 and Ptc2) and the seventransmembrane receptor smoothened (Smo). The Hh signal is then conveyed from Smo to the nucleus, affecting gene expression via the Gli family of transcription factors, thereby regulating a variety of cellular activities, including cell fate determination, proliferation, migration, polarity, and gene expression (McMahon et al., 2003; Ahn and Joyner, 2005; Cousin et al., 2007; Zhang et al., 2011). Purmorphamine and cyclopamine are classical agonists and inhibitors of the Hh signaling pathway and act downstream of Ptc by binding directly to Smo and changing its conformation (Taipale et al., 2000; Chen et al., 2002; Sinha and Chen, 2006; Wu et al., 2002). In mammals, Hh activation inhibits the adipogenesis of 3T3-L1, NIH-3T3, and pluripotent mesenchymal cells, while blocking the Hh pathway and stimulating adipogenesis (Cousin et al., 2007). Hedgehog signals act early in the adipogenic cascade, upstream of the peroxisome proliferator-activated receptor- $\gamma$ (PPAR- $\gamma$ ), possibly by altering the potential fates of precursor cells (Suh et al., 2006). In addition, Hh signals induce the 
expression of osteogenic markers in 3T3-L1 adipogenic cells and pluripotent mesenchymal cells (Spinella-Jaegles et al., 2001; Suh et al., 2006; James et al., 2010). There is a striking difference in the adipocyte differentiation process of rodent and human mesenchymal stem cells (MSC). In humans, Hh signaling alters adipocyte maturation of MSC, whereas it affects only the early differentiation of MSC in rodents (Suh et al., 2006; Fontaine et al., 2008). These results suggest that roles of Hh signaling pathway in the development of fat may be different for individual species.

Pigs are ideal animal models for the study of fat deposits. Although much has been learned about the regulatory mechanism of adipogenic differentiation in porcine adipose-derived mesenchymal stem cells (AMSC), relatively little is known about the mechanism by which the Hh signaling pathway regulates adipogenic differentiation in porcine AMSC. Therefore, this study investigated the effects of the Hh signaling pathway on adipogenic differentiation potential using porcine AMSC. The results will lay a foundation for further revealing the mechanism of the Hh signaling pathway in regulating fat formation, and provide an important scientific basis for the cultivation of high-quality lean pig breeds.

\section{Material and Methods}

The pig specimens were purchased from a local pig breeding farm, and they permitted the porcine parts to be used for the scientific and educational research in our laboratory. The treatment of porcine samples and all procedures in the study were performed according to the Regulations for the Administration of Affairs Concerning Experimental Animals (Ministry of Science and Technology, China; Revised in June 2004) and approved by the local Ethical Committee.

Five grams of dorsal subcutaneous adipose tissues were removed from a 28-day-old female Danish Landrace piglet under sterile conditions, and porcine AMSC were isolated using the method described by Zhang et al. (2013). Briefly, adipose tissue was promptly washed in PBS, then was minced into approximately $1-\mathrm{mm}^{3}$ sections, and enzymatically dissociated in Dulbecco's Modified Eagle Medium/F12 (DMEM/F12) with $0.09 \%$ collagenase type I and $10 \%$ fetal bovine serum (FBS, Life Technologies, Carlsbad, CA, USA). After incubating at $37^{\circ} \mathrm{C}$ for $90 \mathrm{~min}$, the dissociation was terminated by washing medium (DMEM/ F12 with 10\% FBS), followed by centrifugation for $5 \mathrm{~min}$ $(320 \times g)$. Pellet was resuspended with washing medium and sequentially filtered through nylon mesh to remove the tissue debris. After washing three times, the cells were suspended with DMEM/F12 containing 10\% FBS, $50 \mathrm{mg} / \mathrm{mL}$ vitamin $\mathrm{C}$, and $10 \mathrm{ng} / \mathrm{mL}$ basic fibroblast growth factor (bFGF, PeproTech, Rocky Hill, NJ, USA), seeded in $60 \mathrm{~mm}$ cell culture dishes and cultured at $37{ }^{\circ} \mathrm{C}, 5 \% \mathrm{CO}_{2}$ in a humidified incubator. Culture medium was changed every three days until reaching 80 to $90 \%$ confluency.

The AMSC were seeded in growth medium at $2 \times 10^{5}$ cells/well in six-well tissue culture plates with a medium volume of $2 \mathrm{~mL}$ per well. At three days post-confluent, adipogenic differentiation in AMSC was induced by switching to adipogenic medium including 5\% FBS, $100 \mathrm{IU} / \mathrm{mL}$ of penicillin, $100 \mu \mathrm{g} / \mathrm{mL}$ of streptomycin $(\mathrm{P} / \mathrm{S}), 1 \mathrm{Mm}$ dexamethasone, $1.7 \mu \mathrm{M}$ insulin, $0.5 \mathrm{Mm}$ isobutylmethylxanthine, and $11 \mu \mathrm{M}$ rosiglitazone in DMEM/F12. Three days later, the medium was changed to maintenance media with $2 \% \mathrm{FBS}, 100 \mathrm{IU} / \mathrm{mL}$ of $\mathrm{P} / \mathrm{S}$, and $0.5 \mathrm{mmol} / \mathrm{L}$ of insulin in DMEM/F12 by completely replacing the spent induction medium. Twenty-four hours later, the medium was changed back to an adipogenic differentiation medium. To optimally differentiate AMSC into adipogenic cells, the cycle of induction/maintenance was repeated three times. After three cycles of induction/ maintenance, the cells were cultured in maintenance media for additional seven days by replacing the medium every three days.

To activate or inhibit the Hh signaling pathway, $2 \mu \mathrm{L}$ of $5 \mu \mathrm{mol} / \mathrm{mL}$ purmorphamine (PM, Selleck, Houston, TX, USA) or cyclopamine (CM, Selleck, Houston, TX, USA) were added to $2 \mathrm{~mL}$ medium when the cells reached the three days post-confluent. Differentiated phenotype of porcine AMSC was observed by phase-contrast microscopy. Lipid accumulation in the cells was visualized and analyzed by oil red $\mathrm{O}$ staining and oil red $\mathrm{O}$ staining extraction according to the method of Bai et al. (2008) with a slight modification. After the specified time, cell culture plates for oil red $\mathrm{O}$ staining were taken out and the medium was removed. Cells were washed three times with PBS and fixed with $10 \%$ formaldehyde for $30 \mathrm{~min}$ at room temperature. After washing three times with PBS, the cells were stained with $0.5 \%$ filtered oil red $\mathrm{O}$ for $30 \mathrm{~min}$ at room temperature. Then, the oil red $\mathrm{O}$ solution was removed, and the cells were washed three times with PBS. Finally, the cell was dried at $37{ }^{\circ} \mathrm{C}$. The differentiated cells were observed under an inverted microscope (Olympus, Shinjuku, Japan) to detect the oil red $\mathrm{O}$ stained cytoplasmic lipid droplets. The steps for oil red $\mathrm{O}$ extraction were similar to those noted above for oil red $\mathrm{O}$ staining. After cells were stained with $0.5 \%$ filtered oil red $\mathrm{O}$ for $30 \mathrm{~min}$ at room temperature, the oil red $\mathrm{O}$ solution was removed. Intracellular triglyceride in 
the cells was extracted with $100 \%$ isopropanol solution of $2000 \mu \mathrm{L}$ for $10 \mathrm{~min}$ in shaker. Finally, a well with DMSO was used to adjust zero, and the OD value of each hole was detected using a spectrophotometer (UV-2102 PC, Unico Instrument Co., Ltd., Shanghai, China) at a wavelength of $500 \mathrm{~nm}$.

At $0,4,8,12$, and 16 days of adipogenic differentiation, cells were harvested and total RNA was isolated by using the RNeasy ${ }^{\circledR}$ Mini Kit (Omega Scientific, Tarzana, CA, USA). Then, the RNA quantity and integrity were confirmed by a NanoDrop 1000 spectrophotometer (NanoDrop Technologies, Wilmington, DE, USA). Approximately $500 \mathrm{ng}$ of the total RNA was amplified by a reverse transcription (RT) reaction with a random hexamer primer mix using the PrimeScript ${ }^{\mathrm{TM}}$ RT Reagent Kit with gDNA Eraser (Takara Bio, Dalian, China) according to the manufacturer's instructions. Then, the complementary DNA (cDNA) was stored at $-20{ }^{\circ} \mathrm{C}$ for further use.

The expression of the targeted genes was determined using a StepOne Plus ${ }^{\mathrm{TM}}$ Real-Time PCR system (Applied Biosystems, Foster City, CA, USA) with a SYBR ${ }^{\circledR}$ Premix Ex Taq $^{\mathrm{TM}}$ (Tli RNaseH Plus) Kit (Takara Bio, Dalian, China). The cDNA samples were subjected to PCR amplification with primers for Gli1, Gli2, Gli3, Smo, Ptc1, Ptc2, C/EBP $\alpha$, PPAR- $\gamma, \beta$-actin (Table 1 ). The PCR reactions of the $20-\mu \mathrm{L}$ system were run using the following protocol: $30 \mathrm{~s}$ at $95{ }^{\circ} \mathrm{C}$; $5 \mathrm{~s}$ at $95^{\circ} \mathrm{C}, 30 \mathrm{~s}$ at $60{ }^{\circ} \mathrm{C}$ for 40 cycles, then $95^{\circ} \mathrm{C}$ for $15 \mathrm{~s}$, $60{ }^{\circ} \mathrm{C}$ for $1 \mathrm{~min}$, and $95{ }^{\circ} \mathrm{C}$ for $15 \mathrm{~s}$. The same conditions were performed in an equal amount of RNAase-free water as the negative control. The comparative $2^{-\Delta \Delta C T}$ method was used to calculate the relative expression level of each targeted gene, with $\beta$-actin serving as the housekeeping gene. Data of RT-PCR were normalized by measuring the average cycle threshold $(\mathrm{Ct})$ ratios between the candidate genes and the control gene ( $\beta$-actin).

At 16 days post-treatment, cells were harvested and cellular protein was extracted in a lysis buffer $(\mathrm{pH} 7.5)$ containing Tris- $\mathrm{HCl}(50 \mathrm{mM})$, Triton ${ }^{\mathrm{TM}} \mathrm{X}-100 \quad(0.5 \%)$, (ethylenedinitrilo) tetraacetic acid $(2 \mathrm{mM}), \mathrm{NaCl}(150 \mathrm{mM})$, and phenylmethanesulfonyl fluoride $(1 \mathrm{mM})$. The protein content was measured according to the method of Peterson (1977), and the proteins were then placed in a diluted SDS sample buffer and denatured for $10 \mathrm{~min}$ at $100{ }^{\circ} \mathrm{C}$. Fifty micrograms of total protein were loaded in each lane, subjected to electrophoresis in $10 \%$ sodium dodecyl sulfate-polyacrylamide gel, and subsequently transferred to PVDF membranes (Millipore Corp, Bedford, MA, USA) by electroblotting. After blocking for $1 \mathrm{~h}$ in defatted $5 \%$ milk, the membranes were incubated for $2 \mathrm{~h}$ with anti-mouseGli1 (Santa Cruz Biotechnology, Dallas, TX, USA) and anti-mouse- $\beta$-actin antibodies (Santa Cruz Biotechnology, Dallas, TX, USA), and then hybridized with goat antimouse secondary antibody conjugated for $2 \mathrm{~h}$ with peroxidase (Santa Cruz Biotechnology, Dallas, TX, USA). The chemical luminescence signals were detected by X-ray film with an ECL Western Blotting System (Amersham Biosciences, Piscataway, NJ, USA).

Data were analyzed using SPSS $^{\circledR}$ version 16.0. Differences among treatments were analyzed using Duncan's multiple-range test. Significant differences were declared at $\mathrm{P}<0.05$, and very significant differences were declared at $\mathrm{P}<0.01$.

Table 1 - Primer sequences for real-time polymerase-chain reaction

\begin{tabular}{|c|c|c|c|c|}
\hline Gene & Primer sequence $\left(5^{\prime}-3^{\prime}\right)$ & Length/bp & GC\% & $\mathrm{Tm} /{ }^{\circ} \mathrm{C}$ \\
\hline Gli1 & $\begin{array}{l}\text { GAAGTCTGAGCTGGATGTGCTGGTG } \\
\text { CATGGATGTGTTCGCTGTTGATGTG }\end{array}$ & $\begin{array}{l}25 \\
25\end{array}$ & $\begin{array}{l}56 \\
48\end{array}$ & $\begin{array}{c}65.3 \\
62\end{array}$ \\
\hline Gli2 & $\begin{array}{l}\text { GGACACACACCACCCTTGAT } \\
\text { GCCTCCTGCTTACAGTCGTC }\end{array}$ & $\begin{array}{l}20 \\
20\end{array}$ & $\begin{array}{l}55 \\
60\end{array}$ & $\begin{array}{l}59 \\
61\end{array}$ \\
\hline Gli3 & $\begin{array}{l}\text { CTGGGCTTTGGAAGAGTGTC } \\
\text { GGTATTGGCATCGGAAGAGA }\end{array}$ & $\begin{array}{l}20 \\
20\end{array}$ & $\begin{array}{l}55 \\
50\end{array}$ & $\begin{array}{l}59 \\
55\end{array}$ \\
\hline Smo & $\begin{array}{l}\text { GTGGGCGGTTACTTCCTCAT } \\
\text { AGGCTAGGGCGATTCTTGAT }\end{array}$ & $\begin{array}{l}20 \\
20\end{array}$ & $\begin{array}{l}55 \\
50\end{array}$ & $\begin{array}{l}59 \\
55\end{array}$ \\
\hline Ptcl & $\begin{array}{l}\text { TTCCTCTTGAAACCCAAAGC } \\
\text { CAAACGCATCCTGAAGTCCT }\end{array}$ & $\begin{array}{l}20 \\
20\end{array}$ & $\begin{array}{l}45 \\
50\end{array}$ & $\begin{array}{l}53 \\
55\end{array}$ \\
\hline Ptc2 & $\begin{array}{l}\text { CAGGGTGGCTTTGACTACG } \\
\text { GAACTGGGCAAACTCCAAGG }\end{array}$ & $\begin{array}{l}19 \\
20\end{array}$ & $\begin{array}{c}57.8 \\
55\end{array}$ & $\begin{array}{l}53 \\
59\end{array}$ \\
\hline$C / E B P \alpha$ & $\begin{array}{l}\text { ACGCAGCCTTACGGAACT } \\
\text { TTGTTTAGTTGGGATTTGCT }\end{array}$ & $\begin{array}{l}18 \\
20\end{array}$ & $\begin{array}{c}55.6 \\
35\end{array}$ & $\begin{array}{l}57.3 \\
51.6\end{array}$ \\
\hline
\end{tabular}

bp - base pair; Tm - melting temperature; GC - guanine, cytosine. 


\section{Results}

The porcine AMSC cultured in the growth medium proliferated to confluence after two days. When cultured in the adipogenic medium, the porcine AMSC underwent differentiation into adipocytes. Multiple lipid droplets would fill in the ADSC after four days of induction (Figure 1a). As the time of induction lasted, the numbers and sizes of the lipid droplets gradually increased (Figure 1b-c). Sixteen days later, mature adipocytes could be observed with oil red O staining (Figure 1d).

To explore the molecular mechanism by which the $\mathrm{Hh}$ signaling pathway regulates adipogenic differentiation of pig AMSC, we analyzed the expression levels of several genes during AMSC differentiation into an adipocyte. In the AMSC, genes that are involved with Hh signaling, including Smo, Gli1, Gli2, Gli3, Ptc1, Ptc2, transcription factor $C / E B P-\alpha$, and $P P A R-\gamma$, were detected (Figure 2). The expression of Gli1 mRNA gradually increased, reached a peak at four days after differentiation, and then declined steadily (Figure 2). The expression of Gli3 and Gli2 mRNA had no significant change during the first four days after adipogenic induction but declined from day 8. At two days after differentiation, the gene expression level of Smo reached a peak and then declined steadily. The expression of $P t c 1$ and Ptc2 mRNA were significantly unchanged during the first four days after adipogenic induction but decreased from day 8 and then gradually increased. In addition, the expression level of the adipocyte characteristic transcription factors $C / E B P-\alpha$ and $P P A R-\gamma$ gradually increased from day 4 after adipogenic induction. These results indicate that Hh signaling was downregulated during the adipocyte differentiation in porcine AMSC.

To study the effects of $\mathrm{Hh}$ signals on adipocyte differentiation in porcine AMSC, the confluent AMSC were treated with adipogenic medium containing $5 \mu \mathrm{mol} / \mathrm{mL}$

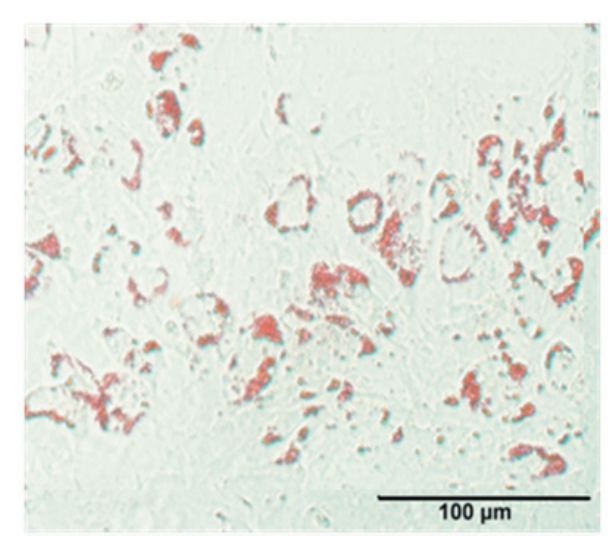

a: $4 d(200 x)$

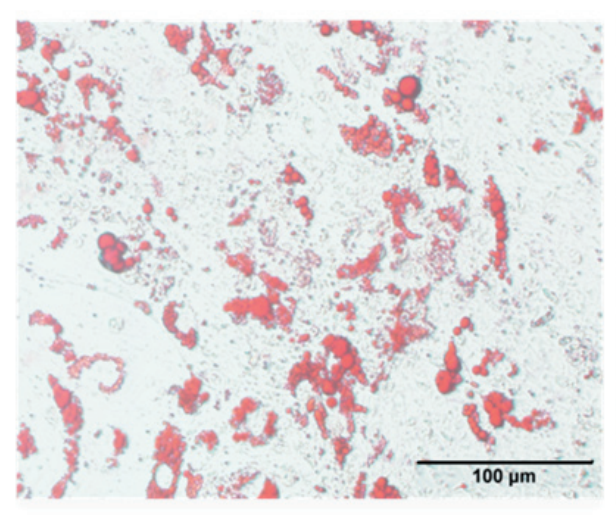

c: $12 d(200 \times)$

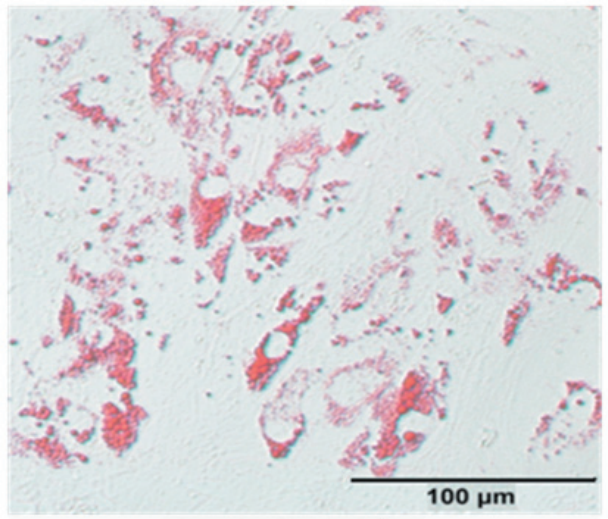

$b: \quad 8 d(200 x)$

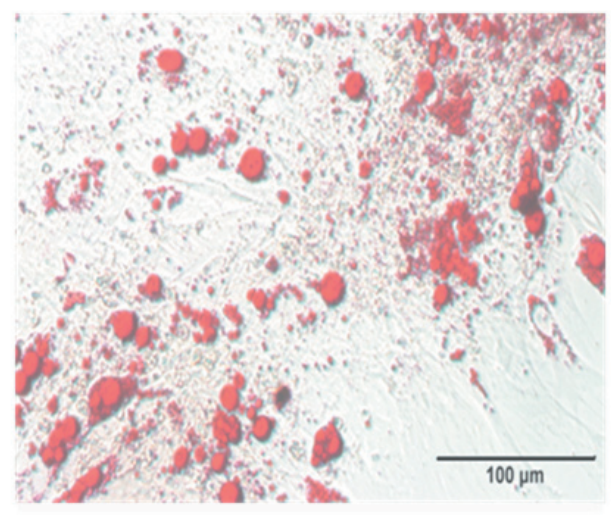

$d: 16 d(200 \times)$

AMSC - adipose-derived mesenchymal stem cells; d - day.

(a) Adipocytes differentiated by culturing in adipogenic medium for four days $(\times 200)$; (b) adipocytes differentiated by culturing in adipogenic medium for eight days $(\times 200)$; (c) adipocytes differentiated by culturing in adipogenic medium for 12 days $(\times 200)$; (d) adipocytes differentiated by culturing in adipogenic medium for 16 days $(\times 200)$,

The mesenchymal stem cells prepared from pig adipose tissue were plated on plastic dishes. After $12 \mathrm{~h}$, the nonattached cells were removed, and the fast-adhesion cells were cultured as porcine AMSC. The differentiation to adipocytes were induced by culturing in adipogenic medium.

Figure 1 - Porcine AMSC in vitro differentiation and fat droplets in cells stained by oil red $\mathrm{O}$. 
purmorphamine or cyclopamine. At $0,4,8,12$, and 16 days post-treatment, cells were harvested, and then the mRNA and protein levels of Gli1 were analyzed (Figure 3a-b). We selected Glil for analysis because it is a major activation marker of the Hh signaling pathway. The mRNA abundance of Glil was significantly increased $(\mathrm{P}<0.05)$ in the purmorphamine-treated group (Figure $3 a-b$ ), and the Gli1 protein level was also markedly upregulated $(\mathrm{P}<0.05)$ by purmorphamine. After treatment with cyclopamine, the mRNA abundance and the protein level of Glil were significantly downregulated $(\mathrm{P}<0.05)$ in comparison with the untreated group. These results indicate that purmorphamine and cyclopamine can effectively activate or inhibit the activity of the Hh signaling pathway.

At 16 days post-treatment, accumulation of lipid droplets was analyzed by oil red $\mathrm{O}$ staining and oil red $\mathrm{O}$ staining extraction. Through oil red O staining, we could notice that AMSC in the control group differentiated into mature fat cells, which were large, round, and filled with fat droplets. In comparison, there were significantly fewer fat droplets in adipocytes in the purmorphamine-treated cells. Both the size and number of fat cells decreased in the purmorphamine-treated cells compared with the control cells (Figure 3c). Results from oil red O extraction showed that triglyceride content significantly decreased in the purmorphamine-treated cells compared with the control cells $(\mathrm{P}<0.01)$. In contrast, the fat droplet and triglyceride content were not markedly altered $(\mathrm{P}>0.05)$ in the cyclopaminetreated cells (Figure 3f). Correspondingly, in comparison with the control cells, the expression of the adipocyte characteristic transcription factors $P P A R-\gamma$ and $C / E B P-\alpha$ was apparently downregulated $(\mathrm{P}<0.05)$ in the purmorphaminetreated cells, while it was not markedly altered $(\mathrm{P}>0.05)$ in the cyclopamine-treated cells (Figure $3 \mathrm{~d}-\mathrm{e}$ ). These results
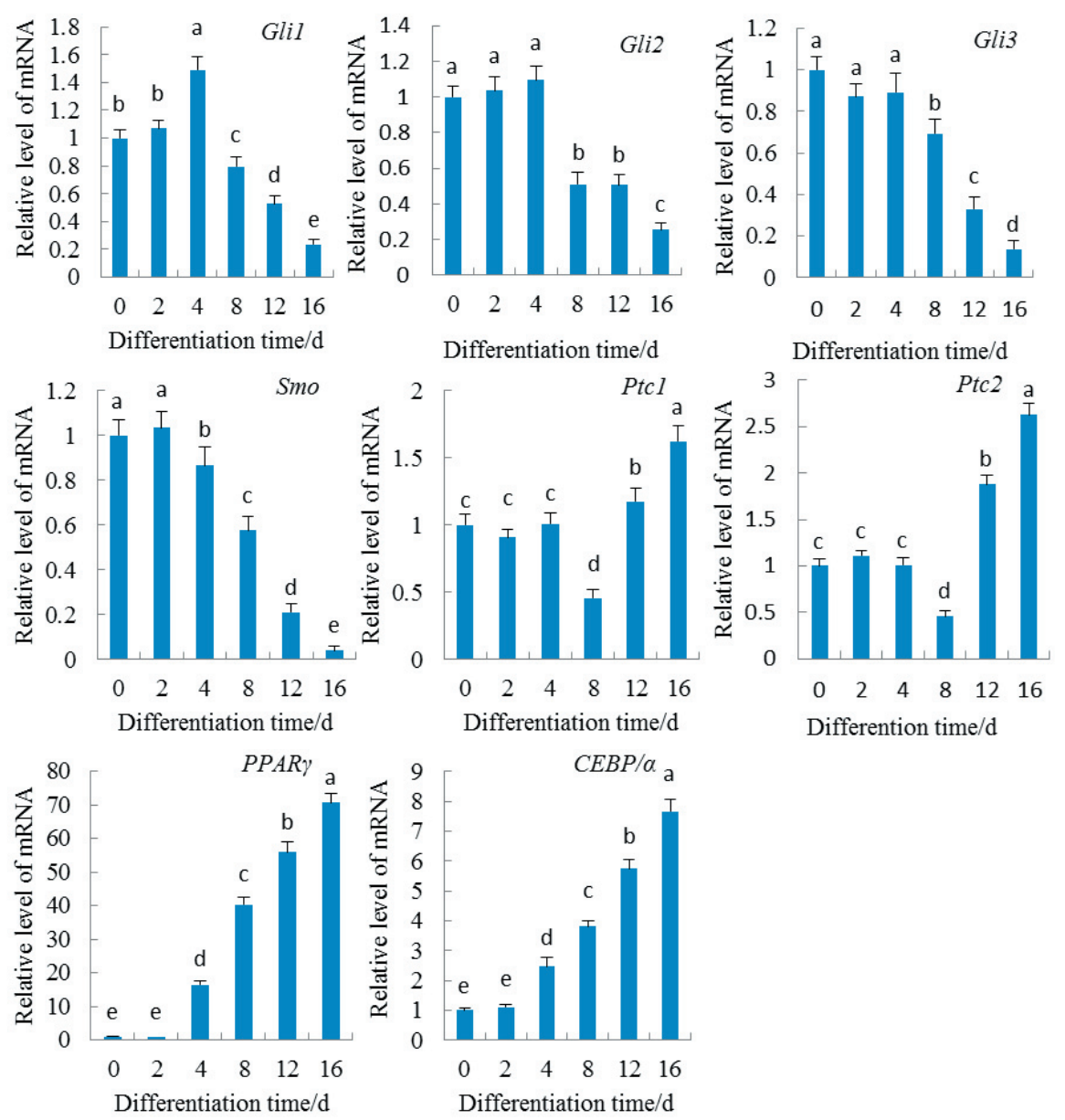

Differention time/d

Gli1, Gli2, Gli3, Smo, Ptc1, Ptc2, C/EBP $\alpha$, and PPAR- $\gamma$ mRNA abundance assigned as a ratio to $\beta$-actin mRNA; $\mathrm{d}$ - day.

The results are represented as mean \pm standard deviation of three independent determinations.

Different letters indicate a statistical difference.

Figure 2 - Sequential expression of genes mRNA during AMSC adipogenic differentiation. 


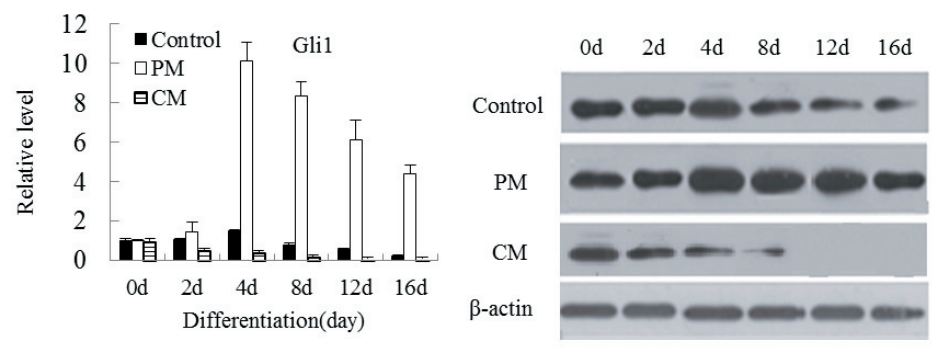

a

b

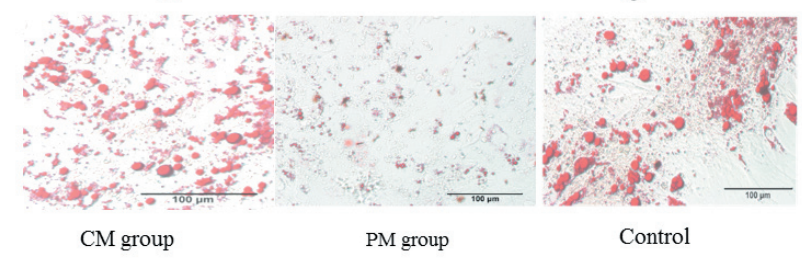

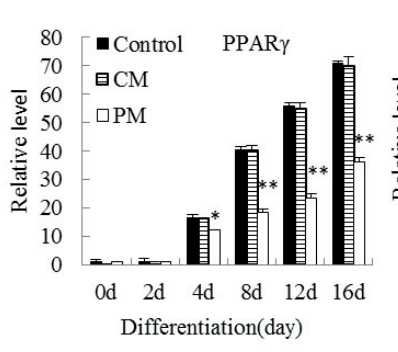

d c

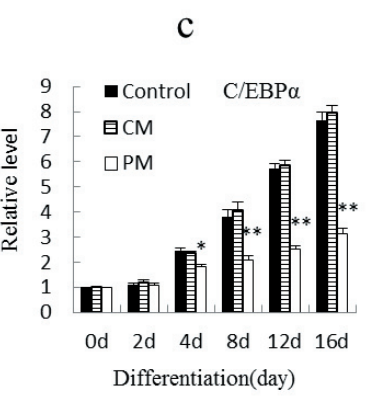

e

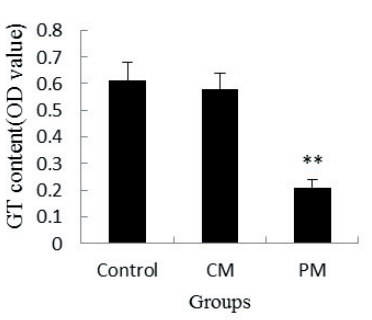

f

CM - cyclopamine; PM - purmorphamine; AMSC - adipose-derived mesenchymal stem cells; $\mathrm{d}$ - day.

Confluent AMSC were cultured in adipogenic medium with $5 \mu \mathrm{mol} / \mathrm{mL}$ purmorphamine or cyclopamine for 16 days. Subsequently, cells were subjected to morphology, gene mRNA, and protein expression analyses.

(a) The mRNA expression levels of Glil were determined by real-time polymerase-chain reaction (PCR); (b) The protein expression levels of Gli1 were determined by western blot analyses; (c) fat droplets in cells were stained by oil red $\mathrm{O}$ on the 16th day $(\times 200)$; (d) triglyceride content analyzed by oil red $\mathrm{O}$ extraction; (e) and (f) the mRNA expression levels of PPAR- $\gamma$ and $C / E B P \alpha$ were determined by real-time PCR.

Results are represented as mean \pm standard error of three independent determinations.

* Indicates a statistical difference $(\mathrm{P}<0.05)$.

** Indicate a statistical difference $(\mathrm{P}<0.01)$.

Figure 3 - Impact of purmorphamine and cyclopamine on porcine AMSC adipogenic differentiation.

indicate that the activation of the Hh signaling pathway inhibited adipogenesis. However, inhibition of the $\mathrm{Hh}$ signaling pathway had no effect on adipogenesis.

\section{Discussion}

Excessive deposition of adipose tissue can lead to a decline in the meat quality of livestock. Fat deposition depends on the differentiation of the fat cells. The fat cells begin with AMSC, which are then targeted to form preadipocytes (Rosen et al., 2000). Adipose-derived mesenchymal stem cells are an ideal model for the study of adipogenesis in vitro because they proliferate rapidly as compared with preadipocytes. To date, research on the mechanism of fat formation has mainly focused on preadipocytes, and some progress has been made in this regard (Lee et al., 2015; Chen et al., 2016; Liu et al., 2016). However, the molecular mechanisms underlying the differentiation of AMSC into adipocytes have not been fully investigated.

Considerable evidence now suggests that the Hh signaling pathway plays a critical role in the adipogenesis (Suh et al., 2006; Cousin et al., 2007; James et al., 2010). Components of the Hh pathway are expressed in mammalian fat, and their levels respond dynamically to adipogenesis and obesity (Suh et al., 2006). The white adipose tissue and the subcutaneous fat pad decrease by activating the Hh signaling pathway in mice (Li et al., 2008). Hedgehog activation was shown to inhibit adipogenesis and stimulate osteoblastogenesis of mouse mesenchymal precursors by 
suppressing $C / E B P-\alpha$ and PPAR- $\gamma$ (Cousin et al., 2006). Research has also shown that $\mathrm{Hh}$ activation altered the morphology of human adipocytes in addition to altering insulin sensitivity (Fontaine et al., 2008). A study of glycerol-3-phosphate dehydrogenase activity and expression of adipocyte marker genes indicated that the activation of Hh signaling by purmorphamine impaired adipogenesis (Fontaine et al., 2008). Studies have also demonstrated that $\mathrm{Hh}$ inhibition is not sufficient to trigger adipogenesis but leads to a decrease in MSC proliferation (Cousin et al., 2007; Plaisant et al., 2011).

The focus of the present study was the role of the Hh signaling pathway during adipogenic differentiation in porcine AMSC. We found that many of the $\mathrm{Hh}$ cascade components, including Smo, the negative regulatory receptors Ptc1 and Ptc2 and the Gli family of Hh transcription factor, were expressed in adipogenic differentiation of porcine AMSC. The expression levels of positive regulators of the Hh pathway (Smo and Glis) decreased during adipogenesis, whereas those of negative regulators (Ptc1 and Ptc2) increased. This is consistent with a previous study in mice (Suh et al., 2006). Gli1 is the major activation marker of the Hh signaling pathway. The mRNA and protein expression levels of Gli1 gradually increased during adipogenic differentiation in porcine AMSC, reaching the maximum on the fourth day before gradually decreasing. The result shows that the activity of the Hh signaling pathway was fully started on the fourth day. Subsequently, the effects of purmorphamine and cyclopamine on the adipogenesis in porcine AMSC were examined. The results indicate that the Hh signaling pathway was activated significantly by purmorphamine and inhibited significantly by cyclopamine. Further, activation of the Hh signaling pathway inhibited the adipogenesis of porcine AMSC, but inhibition of the Hh signaling pathway had no effect on the adipogenic differentiation potential of porcine AMSC, as shown by the method of oil red O staining. This is consistent with a previous study in mice and humans (Suh et al., 2006; Fontaine et al., 2008).

The molecular mechanism of adipogenesis in preadipocyte lines in vitro has been studied extensively (Suh et al., 2006; Bai et al., 2008). Adipogenic induction is followed by rapid and transient induction of $C / E B P-\beta$ and $C / E B P-\delta$. These transcription factors then activate the expression of both $C / E B P-\alpha$ and PPAR- $\gamma$, which induce the expression of other target genes through a positive feedback loop (Rosen et al., 2002; He et al., 2015). In this way, $C / E B P-\alpha$ and $P P A R-\gamma$ play a decisive role in adipocyte differentiation and are important regulators of adipose tissue growth and development (Jia et al., 2015). A previous study reported that multipotential cells expressed adipogenic transcription factors at the physiological level, and that activation of the Hh signaling pathway rapidly suppressed the master adipogenic regulators $C / E B P-\alpha$ and PPAR- $\gamma$ in mouse MSC (Spinella-Jaegles et al., 2001). The results of the present study indicate that porcine AMSC also express $C / E B P-\alpha$ and PPAR- $\gamma$, and that the mRNA expression of $C / E B P-\alpha$ and $P P A R-\gamma$ was significantly suppressed on the fourth day of activation of the $\mathrm{Hh}$ signaling pathway. Based on the morphological changes of cells and the expression change of Gli1, $C / E B P-\alpha$, and PPAR- $\gamma$, we speculate that $\mathrm{Hh}$ signaling can mainly inhibit later adipogenic differentiation of porcine AMSC and has no effect on the early differentiation. This is consistent with a previous study in humans (Fontaine et al., 2008). In addition, it appears that regulation of $C / E B P-\alpha$ and $P P A R-\gamma$ is a primary mechanism by which Hh signaling controls adipogenic differentiation of porcine AMSC.

\section{Conclusions}

The Hedgehog signaling pathway plays an important role in porcine adipogenic differentiation of adiposederived mesenchymal stem cells. Activation of the Hedgehog signaling pathway inhibits adipogenic differentiation of porcine adipose-derived mesenchymal stem cells and may be beneficial for reducing porcine fat deposition.

\section{Acknowledgments}

This work was supported by the Education Department of the Natural Science Foundation of Anhui Province (KJ2013A115), the Open Fund of Anhui Province Key Laboratory of Local Livestock and Poultry Genetic Resource Conservation and Breeding (AKLGRCB2017006), and the Introduction of International Advanced Agricultural Science and Technology Program of the Ministry of Agriculture (2016-Z3).

\section{References}

Ahn, S. and Joyner, A. L. 2005. In vivo analysis of quiescent adult neural stem cells responding to Sonic hedgehog. Nature 437:894-897.

Bai, L.; Pang, W. J.; Yang, Y. J. and Yang, G. S. 2008. Modulation of Sirt 1 by resveratrol and nicotinamide alters proliferation and differentiation of pig preadipocytes. Molecular and Cellular Biochemistry 307:129-140. https://doi.org/10.1007/s11010-0079592-5

Bennett, C. N.; Ross, S. E.; Longo, K. A.; Bajnok, L.; Hemati, N.; Johnson, K. W.; Harrison, S. D. and MacDougald, O. A. 2002. Regulation of Wnt signaling during adipogenesis. Journal of Biological Chemistry 277:30998-31004. https://doi.org/10.1074/jbc.M204527200 
Chen, J. K.; Taipale, J.; Cooper, M. K. and Beachy, P. A. 2002. Inhibition of Hedgehog signaling by direct binding of cyclopamine to Smoothened. Genes \& Development 16:27432748. https://doi.org/10.1101/gad.1025302

Chen, X.; Zhou, B.; Luo, Y.; Huang, Z.; Jia, G.; Liu, G. and Zhao, H. 2016. Tissue distribution of porcine FTO and its effect on porcine intramuscular preadipocytes proliferation and differentiation. PLoS One 11:e0151056. https://doi.org/10.1371/journal.pone.0151056

Cousin, W.; Fontaine, C.; Dani, C. and Peraldi, P. 2007. Hedgehog and adipogenesis: Fat and fiction. Biochimie 89:1447-1453. https://doi.org/10.1016/j.biochi.2007.08.012

Cousin, W.; Dani, C. and Peraldi, P. 2006. Inhibition of the antiadipogenic Hedgehog signaling pathway by cyclopamine does not trigger adipocyte differentiation. Biochemical and Biophysical Research Communications 349:799-803. https://doi.org/10.1016/ j.bbrc.2006.08.112

Farmer, S. R. 2006. Transcriptional control of adipocyte formation. Cell Metabolism 4:263-273. https://doi.org/10.1016/j.cmet.2006.07.001

Fontaine, C.; Cousin, W.; Plaisant, M.; Dani, C. and Peraldi, P. 2008. Hedgehog signaling alters adipocyte maturation of human mesenchymal stem cell. Stem Cells 26:1037-1046. https://doi.org/10.1634/stemcells.2007-0974

He, Y. F.; Liu, F. Y. and Zhang, W. X. 2015. Tangeritin inhibits adipogenesis by down-regulating $\mathrm{C} / \mathrm{EBP} \alpha, \mathrm{C} / \mathrm{EBP} \beta$, and $\mathrm{PPAR} \gamma$ expression in 3T3-L1 fat cells. Genetics and Molecular Research 14:13642-13648. https://doi.org/10.4238/2015.October.28.26

James, A. W.; Leucht, P.; Levi, B.; Carre, A. L.; Xu, Y.; Helms, J. A. and Longaker, M. T. 2010. Sonic Hedgehog influences the balance of osteogenesis and adipogenesis in mouse adiposederived stromal cells. Tissue Engineering Part A 16:2605-2616.

Jia, L.; Pan, Y.; Qiao, L.; Guo, Y. Y.; Hu, Z. Q.; Zhang, F.; Li, B. J. and Liu, W. Z. 2015. Research progress in signaling pathways and microRNA regulation of adipocyte differentiation. Acta Veterinaria et Zootechica Sinica 46:518-525.

Lee, J.; Kim, A. R. and Lee, J. J. 2015. Ramie leaf extracts suppresses adipogenic differentiation in 3T3-L1 cells and pig preadipocytes. Asian-Australasian Journal of Animal Sciences 29:1338-1344. https://doi.org/10.5713/ajas.15.0384

Li, Z.; Zhang, H.; Denhard, L. A.; Liu, L. H.; Zhou, H. and Lan, Z. J. 2008. Reduced white fat mass in adult mice bearing a truncated Patched 1. International Journal of Biological Sciences 4:29-36.

Liu, S.; Sun, G.; Yuan, B.; Zhang, L.; Gao, Y.; Jiang, H.; Dai, L. and Zhang, J. 2016. miR-375 negatively regulates porcine preadipocyte differentiation by targeting BMPR2. FEBS Letters 590:1417-1427. https://doi.org/10.1002/1873-3468.12169

McMahon, A. P.; Ingham, P. W. and Tabin, C. J. 2003. Developmental roles and clinical significance of hedgehog signaling. Current Topics in Developmental Biology 53:111-114.

Peterson, G. L. 1977. A simplification of the protein assay method of Lowry et al. which is more generally applicable. Analytical Biochemistry 83:346-356.
Plaisant, M.; Giorgetti-Peraldi, S.; Gabrielson, M.; Loubat, A.; Dani, C. and Peraldi, P. 2011. Inhibition of hedgehog signaling decreases proliferation and clonogenicity of human mesenchymal stem cells. PLoS One 6:e16798. https://doi.org/10.1371/journal.pone.0016798

Poulos, S. P.; Dodson, M. V.; Culver, M. F. and Hausman, G. J. 2016. The increasingly complex regulation of adipocyte differentiation. Experimental Biology and Medicine (Maywood) 241:449-456.

Prestwich, T. C. and MacDougald, O. A. 2007. Wnt/ $\beta$-catenin signaling in adipogenesis and metabolism. Current Opinion in Cell Biology 19:612-617. https://doi.org/10.1016/j.ceb.2007.09.014

Rosen, E. D. and MacDougald, O. A. 2006. Adipocyte differentiation from the inside out. Nature Reviews Molecular Cell Biology 7:885-896

Rosen, E. D.; Walkey, C. J.; Puigserver, P. and Spiegelman, B. M. 2000. Transcriptional regulation of adipogenesis. Genes \& Development 8:1293-1307.

Rosen, E. D.; Hsu, C. H.; Wang, X.; Sakai, S.; Freeman, M. W.; Gonzalez, F. J. and Spiegelman, B. M. 2002. C/EBPalpha induces adipogenesis through PPARgamma: a unified pathway. Genes \& Development 16:22-26. https://doi.org/10.1101/gad.948702

Sinha, S. and Chen, J. K. 2006. Purmorphamine activates the Hedgehog pathway by targeting Smoothened. Nature Chemical Biology 2:29-30.

Spinella-Jaegles, S.; Rawadi, G.; Kawai, S.; Gallea, S.; Faucheu, C.; Mollat, P.; Courtois, B.; Bergaud, B.; Ramez, V.; Blanchet, A. M.; Adelmant, G.; Baron, R. and Roman-Roman, S. 2001. Sonic hedgehog increases the commitment of pluripotent mesenchymal cells into the osteoblastic lineage and abolishes adipocytic differentiation. Journal of Cell Science 114:2085-2094.

Suh, J. M.; Gao, X.; McKay, J.; McKay, R.; Salo, Z. and Graff, J. M. 2006. Hedgehog signaling plays a conserved role in inhibiting fat formation. Cell Metabolism 3:25-34. https://doi.org/10.1016/ j.cmet.2005.11.012

Taipale, J.; Chen, J. K.; Cooper, M. K.; Wang, B.; Mann, R. K.; Milenkovic, L.; Scott, M. P. and Beachy, P. A. 2000. Effects of oncogenic mutations in Smoothened and Patched can be reversed by cyclopamine. Nature 406:1005-1009.

Wu, X.; Ding, S.; Ding, Q.; Gray, N. S and Schultz, P. G. 2002. A small molecule with osteogenesis-inducing activity in multipotent mesenchymal progenitor cells. Journal of the American Chemical Society 124:14520-14521.

Zhang, Y.; Mao, F.; Lu, Y.; Wu, W.; Zhang, L. and Zhao, Y. 2011. Transduction of the Hedgehog signal through the dimerization of Fused and the nuclear translocation of Cubitus interruptus. Cell Research 21:1436-1451.https://doi.org/10.1038/cr.2011.136

Zhang, Y.; Wei, C.; Zhang, P. F.; Li, X.; Liu, T.; Pu, Y.; Li, Y. S.; Cao, Z. B.; Cao, H. G.; Liu, Y.; Zhang, X. R. and Zhang, Y. H. 2013. Efficient reprogramming of naïve-like induced pluripotent stem cells from porcine adipose-derived stem cells with a feederindependent and serum-free system. PLoS One 9:e85089. https://doi.org/10.1371/journal.pone.0085089 